\title{
Arsenic and Iron in the Finger and Foot Muscle from Blackfoot Disease Patients
}

\author{
Wang Chin-Thin ${ }^{\dagger}$, Shih Tai-Ping **, Huang Kuo-Kuang *, Tsai Yung-Yuch *** , Wang Ren-Tse * \\ and Huang Chin-Wang *** \\ * Ta-Jen Pharmaceutical College Ping-Tong, Taiwan, R. O. C. \\ ** Department of Pathology Tai-chung Veterans General Hospital. Taiwan, R. O.C. \\ *** Department of Chemistry Chun Yuan Christian University, $R$ O.C.
}

\begin{abstract}
Atomic absorption spectrophotometric method, for determination of arsenic and iron concentration in finger and foot muscles from Blackfoot Disease Patients(BFDPs), by amputation were developed. Thirty-four cases of BFDPs, at the most strict clinical examination and thirty cases of Non-BFDPs(NBFDPs) from the traffic accidents. NBFDPs from the same district were compared as the controls.

Arsenic has been claimed to be major causative agents of Blackfoot Disease(BFD) in the south-western coast of Taiwan. We published several papers on this and presented a conception that, as with the increase in clinical stages from the zero, first, second, third and fourth, the increase in the arsenic concentration in blood, hair and urine accompanies as the BFD progressed, although at the third and fourth stages, arsenic decrease might be induced by the antagonistic effect of selenium, zinc and iron. For the purpose to prove this, the study was carried out to check whether at the fourth stage, the concentration of arsenic in BFDPs finger and foot muscles by amputation are higher than that of NBFDPs and whether it is also the case with the blood of BFDPs. The arsenic in muscles of finger and foot of BFDPs by amputation was more than 10 times higher than the NBFDPs at the rate of $0.80 \pm 0.57 \mu \mathrm{g} / \mathrm{g}>0.07 \pm 0.05 \mu \mathrm{g} / \mathrm{g}$ and they were also about 8 times higher than the blood of BFDPs at the fourth clinical stages at the rate of $0.80 \pm 0.57 \mu \mathrm{g} / \mathrm{g}>0.091 \pm 0.052 \mu \mathrm{g} / \mathrm{ml}$. Both of them had significantly difference with $\mathrm{P}<0.01$. These evidences directly indicated that arsenic might be a major causative agent of BFD.

The iron in muscles of finger and foot of BFDPs by amputation were also about 2 times higher than that of NBFDPs at the rate of $39.63 \pm 23.54 \mu \mathrm{g} / \mathrm{g}>19.82 \pm 7.61 \mu \mathrm{g} / \mathrm{g}$ and had a significance difference with $\mathrm{P}<0.05$. These results were on the contrary to the blood, when compared with the blood iron concentration in BFDPs at fourth stage and NBFDPs. The NBFDPs were higher than the BFDPs at the rate of $553.28 \pm 92.96 \mu \mathrm{g} / \mathrm{ml}>$ $510.71 \pm 163.52 \mu \mathrm{g} / \mathrm{ml}$. Therefore iron may have some antagonistic effect to arsenic toxicity for the BFDPs and this fact is worthy of more academic study of the BFD in clinical application.
\end{abstract}

Key words Blackfoot disease, muscles, antagonistic effect, arsenic, iron

Blackfoot disease(BFD) is one of the endemic area disease, which prevailed on the south-westem coast of Taiwan. According to the early report study on BFD, there are more than 1,600 Blackfoot Disease Patients(BFDPs) in Taiwan since 1911. Most BFDPs concentrate in Tainan in Chia-yi county. BFD is one kind of chronic peripheral vascular disease with the symptoms of insidious onset numbness or coldness; localized ulceration and subsequent gangrenous changes, giving the characteristic black coloration of dry gangrene. Most of the BFDPs are permanently maimed as a result of spontaneous or artificial amputation of a portion of the affected extremity. ${ }^{1-6}$

BFD is thought to be related to the presence in artesian drinking water of high concentration of arsenic, silicate, iron, nickel and certain fluorescent compounds. ${ }^{7-10}$

Among of this factors, arsenic is still regarded to be the primary suspect and owing to this point of view, BFDPs with advanced clinical symptoms should therefore have higher arsenic concentration in blood, 
but our preliminary results showed a decrease of arsenic in the advanced clinical stages. ${ }^{11-13}$

Table 1. The Different Stages of Blackfoot Disease Classified Standard in Provincial of Chia-Yi Hospital Taiwan. ${ }^{1415}$

\begin{tabular}{|c|c|}
\hline Different stages & Symptom \\
\hline Zero & $\begin{array}{l}\text { Spontaneous or artificial } \\
\text { Amputation foot or finger } \\
\text { patient of the endemic area } \\
\text { people }\end{array}$ \\
\hline $\begin{array}{l}\text { First } \\
\text { Second }\end{array}$ & $\begin{array}{l}\text { Coldness, numbness and pain. } \\
\text { Evidence of slight ulceration and } \\
\text { ganorene. }\end{array}$ \\
\hline Third & $\begin{array}{l}\text { Evidence of strict ulceration and } \\
\text { gangrene. }\end{array}$ \\
\hline Fourth & $\begin{array}{l}\text { Evidence of gangrenous changes } \\
\text { of the affected extremity. }\end{array}$ \\
\hline
\end{tabular}

Table 2. The distribution of specimens

\begin{tabular}{lcc}
\hline & BFDPs & NBFDPs \\
\hline Male & 21 & 19 \\
Female & 13 & 11 \\
Age & $65 \pm 10$ & $45 \pm 15$ \\
\hline
\end{tabular}

In order to answer this question, we determined arsenic, selenium, copper, zinc and iron in blood, hair and urine of BFDPs at different clinical stages and we found the good explanation "the antagonistic effect between arsenic and selenium, zinc and iron", for the $B F D$. For the purpose to make more advanced study to prove that arsenic is the primary causative agent of BFD. This experiment was carried out to check weather the concentration of arsenic in finger and foot muscles of BFDPs by amputation at the fourth stages are higher than that of NBFDPs and blood arsenic concentration of the BFDPs at the fourth stages without amputation. Moreover ? to prove the antagonistic effect of iron to arsenic. Determination of iron in finger and foot muscles of BFDPs by amputation at the fourth stages were also carried out to see whether ? higher than that of BFDPs blood iron concentration in the fourth stage without amputation or not was also checked.

\section{Experimental}

Finger and foot muscle tissue collection

Thirty-four cases of BFDPs finger and foot muscles were collected from endemic areas(Chia-yi hospital) at fourth clinical stages, according to the criteria set by MD. C. T. Lin $^{1415}$ Chia-yi hospital. Most of those BFDPs had consumed the well water for at least thirty years. ${ }^{16}$ (the criteria of standard in Chia-yi hospital. as shown in Table1.) and thirty cases of NBFDPs Finger or foot muscles without known history of exposure to arsenic from the traffic accidents were used as control. Even distributions of sex and age groups are shown in Table 2. These samples were collected from Veterans General Hospital Tai-chung and Chia-yi hospital in Taiwan.

\section{Chemicals and Biological Standards}

Suprapure grade reagents of $E$. Merck and highly purified water (18M $\Omega$ ) were used. Stock solutions contained $1,000 \mathrm{mg} / \mathrm{l}$ of arsenic and iron. The working standard solutions were prepared from Merck Titrisol standards by diluting with highly purified water. Containers made of quartz, Teflon, or polypropylene were used throughout. They were immersed in $8 \mathrm{~N}$ $\mathrm{HNO}_{3}$ over night and washed with several changes of distilled water.

\section{Analytical Methods ${ }^{11-13}$}

Atomic absorption spectrophotometer model Z-8200 from Hitachi Japan were used. Flame type for iron and its accessory Hydride Formation System HFS-2 were used for determining of arsenic. CEM-MD 2000 Microwave digester (USA) was used for tissue digestion.

\section{Sample Pretreatment ${ }^{11-13}$}

Five grams (wet weight) of Finger and foot muscles tissue had been carefully washed by the $100 \mathrm{ml}$ of deionised water for three times, 15 minutes each in order to remove the outer trace elements. The sample was filtered under to remove the water for $\mathbf{1 0}$ minutes before digestion. ${ }^{17}$ Accurately weight $2.0000 \pm 0.2000$ $\mathrm{g}$ of finger and foot muscles in a digestion vessel, $10 \mathrm{ml}$ of Conc. $\mathrm{HNO}_{3}$ was added. The power output of the digester was set at $20 \%$ for 15 minutes. The digestion was continued at $40 \%$ of power for 10 minutes, and kept the power to $60 \%$ until a colorless solution was obtained(estimated around $15 \mathrm{~min}$.).

The digests was diluted to $50 \mathrm{ml}$ with highly purified deion water. Aliquots then were taken for flame modes of atomic absorption for iron and hydride mode of flame furnace atomic absorption spectrophotometer for arsenic.

\section{Statistical Analysis}

In this study, non-parametric methods were in a few cases more reliable than the parametric, but for the conceptual simplicity and ease of comparison parametric analysis was used instead. Thus, the changes in the clinical findings within groups were tested for the significance by two-sample t-test analysis. Means between the two group were subjected to two side 
analysis of variance and compared by Gosset was considered statistically significant. range(Student's t-test range). A p-value less than 0.05

Table. 3 Comparisons of muscles arsenic and iron concentration in blackfoot disease patients and Non-blackfoot disease patients from finger and foot by amputation.

\begin{tabular}{|c|c|c|c|c|}
\hline & \multicolumn{2}{|c|}{ Concentration } & \multirow{2}{*}{$\begin{array}{l}\text { Deviation between } \\
\text { BFDPs and NBFDPs } \\
(\%)\end{array}$} & \multirow[b]{2}{*}{$p$ value(t-test) } \\
\hline & BFDPs & NBFDPs & & \\
\hline $\begin{array}{l}\text { Arsenio }(\mu \mathrm{g} / \mathrm{g}) \\
\text { Iron } \quad(\mu \mathrm{g} / \mathrm{g})\end{array}$ & $\begin{array}{r}0.80 \pm 0.57 \\
39.63 \pm 23.54\end{array}$ & $\begin{array}{r}0.07 \pm 0.05 \\
19.82 \pm 7.61\end{array}$ & $\begin{array}{r}+1042 \\
+99\end{array}$ & $\begin{array}{l}p<0.01 \\
p<0.05\end{array}$ \\
\hline
\end{tabular}

Each value is the meantS.D. of 3 runs

SD: Standard deviation

BFDPs : blackfoot disease patients

NBFDPs : Non- blackfoot disease patients

Table. 4 Comparisons of arsenic concentration in BFDPs muscles by amputation from finger and foot with the BFDPs at the fourth clinical stage in blood.

\begin{tabular}{|c|c|c|c|c|}
\hline \multicolumn{3}{|c|}{ Concentration } & \multirow{2}{*}{$\begin{array}{c}\text { Deviation between } \\
\text { BFDPs muscle and BFDPs blood } \\
\text { (\%) }\end{array}$} & \multirow[b]{2}{*}{$p$ value $(t-t e s t$} \\
\hline & $\begin{array}{l}\text { BFDPs muscles } \\
(\mu g / g)\end{array}$ & $\begin{array}{c}\text { BFDPs blood } \\
(\mu \mathrm{g} / \mathrm{ml})\end{array}$ & & \\
\hline Arsenic & $0.80 \pm 0.57$ & $0.091 \pm 0.052$ & +779 & $\mathbf{P}<0.01$ \\
\hline
\end{tabular}

Each value is the meantS.D. of 3 runs

Table. 5 Comparison the muscles iron concentration with BFDPs and NBFDPs by amputation from finger and comparison the iron concentration with the blood of NBFDPs and BFDPs at fourth clinical stage.

\begin{tabular}{lcccc}
\hline & \multicolumn{2}{c}{ Concentration } & \multicolumn{2}{c}{ Concentration } \\
& $\begin{array}{l}\text { NBFDPs blood } \\
(\mu \mathrm{g} / \mathrm{ml})\end{array}$ & $\begin{array}{c}\text { BFDPs blood } \\
(\mu \mathrm{g} / \mathrm{ml})\end{array}$ & $\begin{array}{c}\text { NBFDPs muscles } \\
(\mu \mathrm{g} / \mathrm{g})\end{array}$ & $\begin{array}{c}\text { BFDPs muscles } \\
(\mu \mathrm{g} / \mathrm{g})\end{array}$ \\
\hline $\begin{array}{l}\text { Iron } \\
\text { P value(t-test })\end{array}$ & $\mathrm{P}>0.05$ & $510.71 \pm 163.52$ & $19.82 \pm 7.61$ & $39.63 \pm 23.54$ \\
\hline
\end{tabular}

Each value is the mean \pm S.D. of 3 runs

The results were expressed as meantSD. Statistical analysis was performed by STATGRAFIC statistic package USA.

\section{Results and Discussion}

\section{Standard Curves}

Standard curves of iron and arsenic were obtained by analyzing NBFDPs finger and foot muscles. To $1 \mathrm{ml}$ of the sample was added the following: $0.2,0.4,1,2$, and $4 \mu \mathrm{g}$ of iron and 2, 4, 10, 20 and $40 \mathrm{ng}$ of arsenic. The results showed good linear relationships with changes in concentration. All elements provided good linearity with the relation coefficient $>0.9998$.

\section{Data Precision and Recovery (Accuracy)}

For checking data quality, human finger and foot muscles reference material should be analyzed would be the best, but there was no human finger and foot muscles reference material. So we sparked the arsenic and iron into the NBFDPs finger and foot muscles and calculated the recoveries as the accuracy. The best precision as expressed in \% coefficient of variation (CV\%). The recoveries and precision of analyses from the NBFDPs finger and foot muscles were $99.2 \%$ for iron and $\mathrm{CV} \%<5.0 \%$.

Arsenic was shown a lower recovery $92.0 \%$ and a higher CV\% $12.0 \%$ than the iron.

Arsenic and Iron Concentration in the BFDPs and NBFDPs Finger and Foot Muscles

Table 3. shows the analyses results of BFDPs and NBFDPs in finger and foot muscles by amputation. The result shows that, arsenic concentration, of BFDPs was 10 times higher than those of NBFDPs at the rate of $0.80 \pm 0.57 \mu \mathrm{g} / \mathrm{g},>0.07 \pm 0.05 \mu \mathrm{g} / \mathrm{g}$ with $\mathrm{p}<0.01$; and fell within $+1042 \%$ deviation.

Iron concentrations of BFDPs were also two times greater than those of NBFDPs at the rate of $39.63 \pm 23.54>19.82 \pm 7.61 \mu \mathrm{g} / \mathrm{g}$ with $\mathrm{p}<0.05$ and fell 
within $+99 \%$ deviation. The BFDPs at the fourth clinical stage obviously had a higher arsenic and an higher iron concentration than those of NBFDPs.

Comparison the Arsenic and Iron Concentration in Finger and Foot Muscles by Amputation of BFDPs with the BFDPs Blood at the Fourth Clinical Stages

Table 4. showed the analyses results obtained from BFDPs finger and foot muscles by amputation and BFDPs blood at the fourth clinical stages. It indicates that the arsenic concentration in BFDPs finger and foot muscles by amputation at the fourth clinical stage were 8 times higher than those in blood of BFDPs ${ }^{11}$ at the rate of $0.80 \pm 0.57 \mu \mathrm{g} / \mathrm{g},>0.091 \pm 0.052 \mu \mathrm{g} / \mathrm{ml}$ with $p>0.01$. This reason may cause by arsenic having bond with some sulfhydryl group in finger and foot muscles protein $^{18-19}$.

Table 5. Showed iron concentration in finger and foot of BFDPs by amputation were also about 2 times high than that of NBFDPs at the rate of $39.63 \pm 23.54$ $\mu \mathrm{g} / \mathrm{g}>19.82 \pm 7.61 \mu \mathrm{g} / \mathrm{g}$ and had a significantly difference with $p<0.05$. The results are quite in contrast with the concentration in blood; the blood iron concentration in BFDPs at fourth stages and NBFDPs ${ }^{11}$ at the rate of $533.28 \pm 92.96 \mu \mathrm{g} / \mathrm{ml}$ and $510.71 \pm 163.52$ $\mu \mathrm{g} / \mathrm{ml}$, respectively, and are at a similar level.

Therefore iron may have some antagonistic effect to arsenic toxicity to the BFDPs and this fact worthy of more academic study on the BFD clinical application.

\section{Conclusion}

Arsenic in blood and hair specimens was found to increase as the clinical stages of the BFDPs steps up from the first to second stages. After that, then subsequently decreased in the later stages. ${ }^{11-12}$ But, when compared with the BFDPs arsenic concentration in finger and foot muscles by amputation at the fourth stage was found had a significantly high arsenic concentration than the NBFDPs at the rate of $0.80 \pm 0.57 \mu \mathrm{g} / \mathrm{g},>0.07 \pm 0.05 \mu \mathrm{g} / \mathrm{g}$ with $\mathrm{p}<0.01$. We suspected arsenic may bonding with some sulfhydryl group of protein in the finger and foot muscles in BFDPs and destroys these tissues. Therefore arsenic may be as a major cause agent of BFD.

Iron concentration decreased through out the zero to the fourth stages, when analyzed with blood and hair of BFDPs. The decrease of iron concentration at all stages may be attributed to an antagonistic effect to arsenic. This may warrant of further academic and clinical study.
The work was financially supported by Tai-chung Veterans General Hospital Taiwan R. O. C.

\section{References}

1. Tseng, W. P. J., Formosan Med. Assoc., 7, 11 (1973).

2. Yeh, S. \& How, S. W. Report, Institute of Pathology, National Tatwan University. 14, 25 (1963).

3. Tseng, W. P., Chen, W. Y. \& Sung, J. L., Memoirs of College of Medicine of the National Taiwan Univ., 7, 1 (1961).

4. Chen, K. P. \& Wu, H. Y., J. Formosan, Med. Assoc., 61, 611(1962).

5. Tseng, W. P., J. Nat. Cancer Inst., 40, 453 (1968).

6. Chen, K. P., Memoirs College of Medicine Nat. Taiwan Univ., 8, 115 (1962).

7. Lo, M. C., Hsen, Y. C. \& Lin, B. K., The second report on investigation of arsenic content in underground water in Taiwan province. Taipei. Provincial Institute of Environmental Samitation 1977.

8. Lu, F. J., National Science Council Monthly. 6, 388 (1978).

9. Lu, F. J. \& Liu, T. M., J. Formosan, Med. Assoc., 85, 352(1986).

10. Lu. F. J., J. Chinese Biochemical Society, 17, 57 (1988)

11. Wang, C. T., Huang, C. W., Chou, S. S., Lin, C. T., Liau, S. W. and Wang R. T., Eur. J. Clin Chem, Clin. Biochem. 31, 759 (1993).

12. Wang, C. T., Huang, C. W., Chou, S. S., Lin, C. T., Liau, S. W. and Wang, R. T., Eur. J. Clin Chem, Clin. Biochem. 32, 107 (1994).

13. Wang C. T., Eur. J. Clin. Chem. Clin. Biochem., 34, 493 (1996).

14. Lin, T. C. and Liau, S. S., Report of blackfoot disease Res., 37, 26 (1991).

15. Lin, T. C. and Lial, S. S., Report of blackfoot disease Res., 35, 1 (1990).

16. Wu, H. Y. \& Chen, K. P., Memoirs College of Medicine National Taiwan Univ., 7, 33 (1961).

17. Hiroshi Yamauchi and Yukio Yamamura, Bull. Environ. Toxicol., 31, 267 (1983)

18. Huper, W. C., Arch Pathol., 38, 162 (1944).

19. Fowler, B. A. "Biological and Envinonmental Effect of Arsenic", 6, 1, Amsterdam 1983. 